\title{
Diabetes Mellitus and the Cardiovascular System
}

\author{
Pavani Kolakalapudia , Bassam Omar ${ }^{\mathrm{a}, \mathrm{b}}$
}

\begin{abstract}
Diabetes mellitus (DM) is an epidemic which affects close to 100 million patients worldwide; the majority being type 2 diabetes mellitus. The rising incidence has resulted in a proportional increase in the frequency of cardiovascular disease attributable to DM, as revealed by various population-based studies. Over the past 50 years, DM has been shown to be an important and independent risk factor in the development of a variety of cardiac conditions, especially vascular disease, primarily through accelerated atherosclerosis. Diabetic neuropathy is a serious complication of DM, which leads to the impairment of cardiovascular autonomic control. Diabetic cardiac autonomic neuropathy results in heart rate abnormalities, exercise intolerance, orthostatic blood pressure abnormalities, QT interval prolongation, silent ischemia and diabetic cardiomyopathy, all of which lead to increased morbidity and mortality related to diabetes. This conditions remains difficult to diagnose and treat, requiring a multifaceted approach. Inflammation appears to play a central role in accelerating many of the injurious effects of DM on the cardiovascular system. Expression of specific inflammatory markers has been directly linked to some of the known harmful effects of DM on the cardiovascular system, in addition to indirectly potentiating the deleterious effects of other major cardiovascular disease risk factors. Hyperglycemia results in increased intracellular glucose which triggers several pro-inflammatory reactions leading to the production of harmful free radicals and the formation of advanced glycation end products. These have been linked to the development of diabetic atherogenic dyslipidemia, in addition to glycation and loss of the protective effect of high density lipoproteins in diabetic subjects, thereby worsening the atherosclerotic burden in DM. Addressing hyperglycemia, therefore, is only one of many vital components in the treatment of diabetes. Traditional risk factors for heart disease and stroke tend to be further potentiated by the presence of DM, however, even after adequate control of hyperglycemia. Clinical evidence and major clinical guidelines address this conundrum by
\end{abstract}

Manuscript accepted for publication November 20, 2015

aDivision of Cardiology, University of South Alabama, Mobile, AL 36617, USA

${ }^{b}$ Corresponding Author: Bassam Omar, Division of Cardiology, University of South Alabama, Mobile, AL 36617, USA.

Email: bomar@health.southalabama.edu

doi: http://dx.doi.org/10.14740/jem324e pointing out unmet needs of adequate cardiovascular protection, and call for aggressive control of risk factors in the diabetic population.

Keywords: Diabetes; Autonomic dysfunction; Diabetic neuropathy

\section{Introduction}

Diabetes mellitus (DM) is an epidemic which affects close to 100 million patients worldwide, up to $10 \%$ with type $1 \mathrm{DM}$, and $90 \%$ type 2 DM. DM is an independent risk factor for the development of coronary disease, principally due to enhanced atherosclerosis $[1,2]$. The increased prevalence of DM has increased the proportion of cardiovascular disease attributable to $\mathrm{DM}$ in the Framingham population over the past 50 years [3]. Although the absolute risk of cardiovascular disease is at least two-fold greater in patients with DM than among persons without diabetes, a $50 \%$ reduction in the rate of incident cardiovascular disease events among adults with diabetes was reported, likely due to the more aggressive treatment of risk factors [4]. The metabolic syndrome, a pre-diabetic manifestation primarily of the ever growing trend of obesity, is in itself a strong predictor of the risk of cardiovascular disease $[5,6]$.

Multiple studies and reviews have examined the detrimental effect of diabetes on the vascular endothelium, and equated diabetes with underlying coronary artery disease with regard to overall cardiovascular risk [7, 8]. The American Heart Association's sixth prevention conference proceedings on diabetes and cardiovascular disease reviewed the prevalence and care of diabetes with regard to risk factor evaluation, treatment and challenges [9]. Cardiovascular disease risk factors in youth with diabetes have been the subject of another more recent scientific statement from the American Heart Association, describing the interplay of multiple cardiac risk factors in the young patients with either type DM, and the therapeutic options [10]. Despite the intensive research and the wealth of information covering diabetes, there remain several areas of uncertainties and unmet needs in the prevention and treatment of diabetic cardiovascular disease.

\section{Case Sample}

A 57-year-old white female was admitted to our hospital with 
dizziness and fatigue. She has been treated for DM for the preceding 8 years, with suboptimal control. She suffered diabetic neuropathy, and sustained a stroke 1 year prior to admission, with mild residual weakness. She denied any rest or exertional chest discomfort or dyspnea; however, she suffered limited mobility. Her medications included atorvastatin $10 \mathrm{mg}$ daily, aspirin $325 \mathrm{mg}$ daily, valsartan $160 \mathrm{mg}$ daily, glimepiride 4 $\mathrm{mg}$ daily in addition to a variable regimen of insulin. Her admission blood pressure was $125 / 74 \mathrm{~mm} \mathrm{Hg}$, heart rate was 88 beats/min and regular, respirations were $20 / \mathrm{min}$ and nonlabored, weight was $202 \mathrm{lbs}$ and height was 5'4" yielding a body mass index of $35 \mathrm{~kg} / \mathrm{m}^{2}$. Fating lipid profile revealed total cholesterol of $130 \mathrm{mg} / \mathrm{dL}$, LDL of $57 \mathrm{mg} / \mathrm{dL}$, HDL of $40 \mathrm{mg} / \mathrm{dL}$ and triglycerides of $166 \mathrm{mg} / \mathrm{dL}$; glucose was 224 $\mathrm{mg} / \mathrm{dL}$ and $\mathrm{A} 1 \mathrm{C}$ was $8.7 \%$. Her troponin I was initially mildly elevated at $0.06 \mathrm{ng} / \mathrm{mL}$, but later trended up to $0.13 \mathrm{ng} / \mathrm{mL}$. Other laboratory tests including renal and hepatic profiles were within normal limits. She underwent echocardiography which revealed normal ejection fraction with localized apical akinesis. CT angiography of the head revealed multiple vascular blockages. Coronary angiography revealed severe mid left anterior descending (LAD) coronary disease, which necessitated stent placement.

This case clearly illustrates the aggressive metabolic effects of DM on the vascular tree, despite the often apparently controlled vascular risk factors including lipids. It also illustrates how the usual markers of atherosclerosis may underestimate the cardiovascular risk in the diabetic population. The association of diabetes with vascular disease and the diagnostic and therapeutic challenges in addressing the residual atherogenic risks will be reviewed to shed some light on this perpetual enigma.

\section{Diabetic Cardiac Autonomic Neuropathy (DCAN)}

Diabetic neuropathy is a very common and lethal complication of DM, causing severe and costly morbidity and increasingly contributing to mortality [11]. Multifactorial approach to its diagnosis and medical treatment is recommended [12]. The etiology appears to be related to the increased oxidative stress in diabetes, leading to the propagation of lipid peroxidation. An anti-inflammatory role for statins has been demonstrated in the treatment of diabetic polyneuropathy [13].

According to the Cardiac Autonomic Neuropathy Subcommittee of the Toronto Consensus Panel on Diabetic Neuropathy, DCAN is defined as the impairment of cardiovascular autonomic control in patients with established DM, excluding other causes [14]. DCAN may cause heart rate abnormalities at rest and with activity leading to exercise intolerance, orthostatic changes in blood pressure and heart rate, QT interval prolongation, diurnal and nocturnal blood pressure changes, silent ischemia and diabetic cardiomyopathy [15].

DCAN is divided into two phases, clinical and sub-clinical. Parasympathetic denervation is often the first impairment, with sustained sympathetic predominance. In the later stages, there is progression to sympathetic denervation resulting in postural orthostatic hypotension. Orthostatic hypotension appears to be one manifestation of severe DCAN due to progres- sive autonomic dysfunction affecting the sympathetic tone [16]. Ineffective heart rate response and inadequate peripheral vasoconstriction occur as a result of abnormalities in the baroreceptor sensitivity and norepinephrine release [17], leading to postural changes in cardiac output and orthostatic dizziness or syncope.

Blunted heart rate variability (impaired respiratory beat to beat variability) is one of the first signs seen in the sub-clinical phase of DCAN. Decreased beat to beat variability during deep inspiration with inhibition of the vagal tone appears to be a reflection of impaired cardiac autonomic (parasympathetic) activity in diabetic patients, which manifests before other clinical symptoms of diabetic neuropathy [18]. A fixed heart rate which does not change with sleep, exercise, or stress has been described as a sign of cardiac denervation [19]. As DCAN progresses, exercise stress testing becomes challenging in cardiac risk assessment of the diabetic patient. Along with blunted heart rate response, inadequate blood pressure and stroke volume augmentation impair exercise tolerance and limit the diagnostic sensitivity of exercise testing. Hence, pharmacologic stress imaging is more often employed, and seems to provide better sensitivity in patients with DCAN to detect ischemia [19].

The level of blood glucose elevation and the duration of diabetes were shown to be associated with the extent of blunting in heart rate variability, especially within the first $5-10$ years of the disease [16]. Although diagnosis, staging and screening for DCAN have recently been proposed, there are no specific therapies to treat or prevent this condition [20].

DCAN may cause diabetic cardiomyopathy due to changes in sympathetic-vagal imbalance, which results in left ventricular hypertrophy and remodeling [16]. At the cellular level, parasympathetic denervation increases the release of catecholamines, leading to mitochondrial uncoupling, and switching energy generation from glucose to free fatty acids. This increases oxygen demand and consumption during cardiac work, eventually resulting in hypertrophy and remodeling [21].

Diastolic dysfunction is often the only abnormality found on echocardiography during the early stages of diabetic cardiomyopathy. Newer modalities such as cardiac MRI are able to detect early stages of DCAN by measuring the torsion (apical rotation of long axis which is followed by rapid untwisting), which is found to be prolonged in diabetic cardiomyopathy due to sympathetic denervation [16].

Studies have shown that diabetic patients experience angina pectoris at rates much lower than non-diabetic patients during exercise stress testing, despite the higher prevalence of coronary disease in diabetic patients [22]. DCAN causes abnormalities in pain perception due to sensory denervation. Diabetic patients with stable angina demonstrate electrocardiographic evidence of silent myocardial ischemia on ambulatory electrocardiographic monitor tests during daily activities [23]. Titrating anti-ischemic medications is, therefore, challenging in this patient population in the absence of angina.

Silent coronary disease is described in up to $23 \%$ of lowrisk diabetic patients, and up to $60 \%$ in high-risk diabetic patients [24]. Silent myocardial infarction has also been described with higher frequency in diabetic patients, and is associated with poorer prognosis [25]. However, whether screening 
diabetic patients would improve outcomes if they are already receiving adequate primary prevention therapy remains unknown [26].

Erectile dysfunction can be a manifestation of significant vascular disease in diabetic patients, which should prompt screening for coronary disease [27]. The stress of undergoing major non-cardiac surgery may also call for ischemia evaluation in diabetic patients to detect silent myocardial ischemia for intensive perioperative management [28].

Sleep disordered breathing is associated with increased cardiovascular morbidity and shares many of the metabolic features of DCAN [29]. Increasing severity of obstructive sleep apnea has been linked to increased prevalence, and worsened control, of the metabolic syndrome and type 2 DM [30].

$\mathrm{DM}$ is also associated with increased risk of sudden cardiac death due to several risk factors, primarily silent ischemia and autonomic dysfunction leading to arrhythmogenic repolarization abnormalities and heart rate variability. Other risk factors associated with sudden death in diabetic patients include diabetic cardiomyopathy, impaired pulmonary response to hypoxia and hypercapnea, hypoglycemia and hypercoagulability [31, 32].

\section{Diabetes and Inflammation/Oxidative Stress}

The role of inflammation in cardiovascular disease has been extensively documented at the basic and clinical level. DM is a major cause for the expression of inflammatory markers, which not only exert direct harm on the cardiovascular system, but also potentiate the negative effects of other cardiovascular risk factors. Hyperglycemia in diabetic patients results in increased intracellular glucose which triggers several pro-inflammatory reactions causing the production of highly toxic oxygen-derived free radicals [33]. Potentiation of NADPH oxidases, endothelial nitric oxide synthase uncoupling, and protein kinase $\mathrm{C}$ signaling have been postulated to increase production of vascular superoxide leading to endothelial dysfunction in diabetic patients [34].

Generation of superoxide in itself activates multiple other inflammatory and oxidative pathways, leading to further generation of superoxide in a self-propagating fashion. Superoxide inactivates the endothelial derive relaxation factor, nitric oxide, resulting in the formation of a highly toxic reactant, peroxynitrite [35]. This results in the depletion of nitric oxide leading to the observed endothelial dysfunction in diabetic patients [36], in addition to the generation of various potent oxygen-derived free radicals which can cause further damage through lipid peroxidation [37].

A role for antioxidants has been demonstrated in restoring endothelium-dependent vasodilation impaired by hyperglycemia in particular [38], and in protection against the toxic effects of reactive oxygen species in general [39]. Hyperglycemia also impairs physiological nitric oxide signaling in diabetic subjects, resulting in decreased endothelial responsiveness to nitric oxide, thereby increasing endothelial dysfunction and propagating the generation and toxicity of reactive oxygen species [40].
These generalized endothelial insults affect other non-cardiac tissues resulting in diabetic nephropathy [41, 42], neuropathy $[43,44]$, and retinopathy [44]. Oxidative stress has also been incriminated in the increase in inflammatory makers in gestational diabetes [45], and in the evolution of Alzheimer's disease [46]. Diabetic cardiomyopathy has been attributed to an apoptotic effect of oxidative stress through activation of pro-inflammatory pathways causing cell death and myocardial dysfunction [47]. DCAN discussed above has also been increasingly linked to the heightened oxidative stress in diabetic patients [48, 49]. The beneficial role for dietary antioxidants in the treatment of diabetic neuropathy and cardiac autonomic neuropathy is also indicative of the role of heightened inflammatory/oxidative stress in this entity [50].

\section{Diabetes and Atherosclerosis}

Diabetes in itself is a major risk factor for the development of atherosclerotic cardiovascular disease [51, 52]. Mechanisms of atherosclerosis in diabetes appear to be unique [53], and heavily influenced by the aforementioned oxidative stress [54, 55]. The formation of advanced glycation end products has also been linked to the development of diabetic atherogenic dyslipidemia [56]. Furthermore, the glycation of high density lipoprotein (HDL) in diabetic subjects tends to decrease its protective functionality, and thereby worsening the atherosclerotic burden of diabetes [57].

Adipokines can directly mediate atherosclerosis by influencing the function of endothelial cells, arterial smooth muscle cells, and macrophages in vessel walls [58]. Adiponectin, which tends to be vasculo-protective against diabetic atherosclerosis, has been shown to decrease in patients with type 2 diabetes, obesity or metabolic syndrome [59, 60]. Although inadequate control of diabetes has mostly been linked to the development of microvascular disease, studies have not shown decrease in macrovascular disease event rates from improved glycemic control in type 2 diabetes [61]. Nevertheless, glycemic control remains essential in controlling the harmful oxidative and inflammatory stress and its impact on atherosclerosis.

Lipid profile in diabetic "atherogenic" dyslipidemia predominantly demonstrates small dense low density lipoprotein (LDL), with elevated triglycerides and low, usually dysfunctional, HDL [62]. The seemingly normal total LDL concentration can be misleading with regard to traditional treatment targets for lipids. Therefore, there should be a comprehensive approach towards the evaluation and control of diabetic vascular atherosclerosis risk factors, as the non-traditional risk factors of inflammation and LDL oxidation tend to be more pronounced than in the non-diabetic population, calling for an individualized approach to account for all risk factors [63].

\section{Diabetic Vasculopathy and Current Therapeu- tics}

It is increasingly evident that addressing hyperglycemia is only one of many important components in the treatment of diabe- 


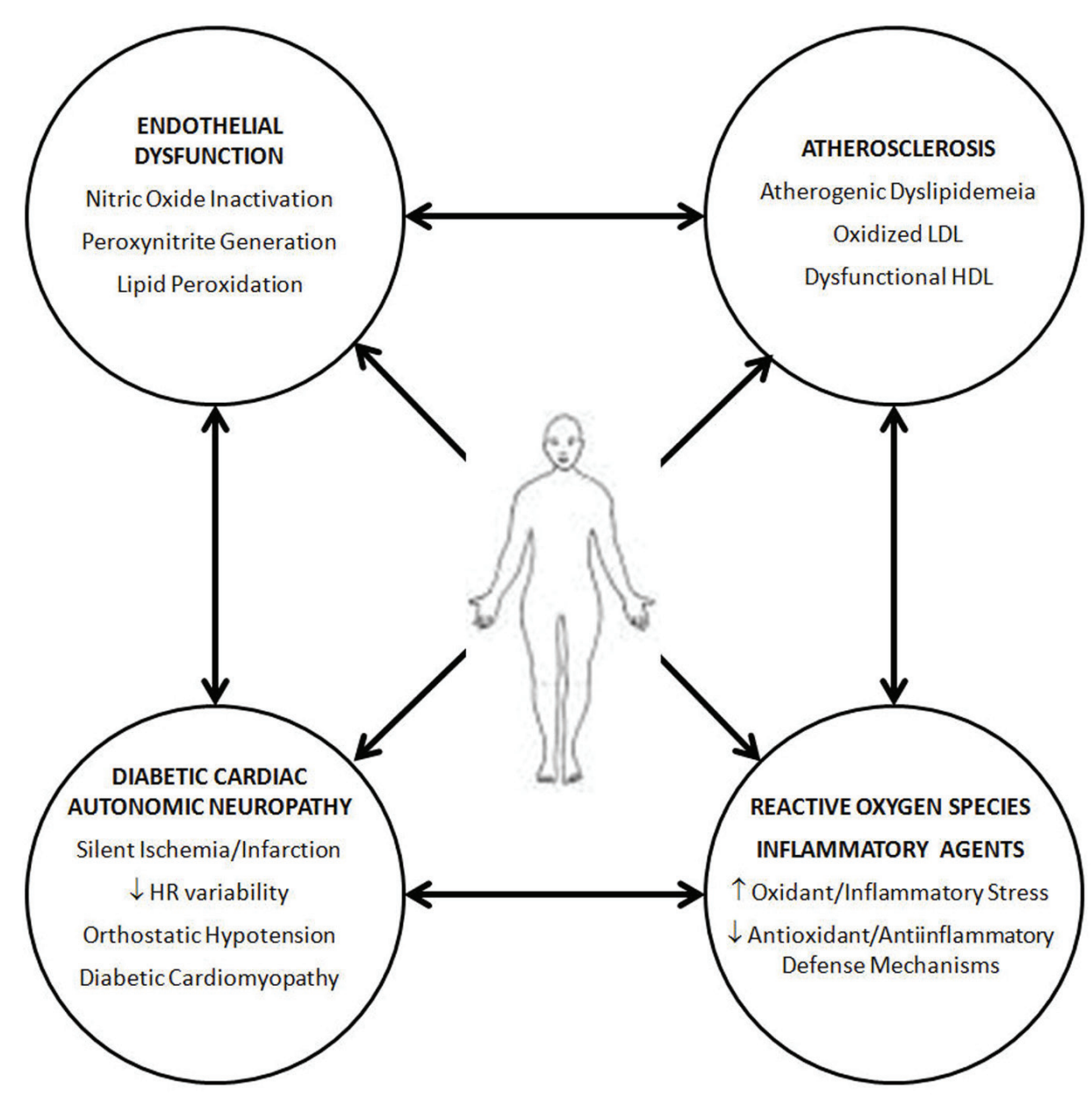

Figure 1. The interplay of several factors in diabetic cardiovascular disease appears to reflect a heightened inflammatory/oxidation stress which affects the entirety of the vascular tree, affecting multiple organs at the microvascular and macrovascular level, in addition to the harmful effects on the autonomic nervous system.

tes. Traditional risk factors for heart disease and stroke tend to be further potentiated by the presence of diabetes, even after adequate control of hyperglycemia. Several clinical trials have surfaced in the past decade addressing the need for proper control of risk factors, and the level of such control, in the diabetic population.

The benefit of statin medications on cardiovascular and stroke outcomes in diabetic patients has been unequivocally demonstrated in multiple clinical trials $[64,65]$. The lack of benefit of the routine administration of non-statin medications (such as niacin and fibrates) has also been shown [66, 67], despite a decrease in LDL and often increase in HDL, likely indicating a pleiotropic anti-inflammatory role for statins. A beneficial role for fibrates, however, may be seen in diabetic patient with very low HDL levels $(<34 \mathrm{mg} / \mathrm{dL})$ or very high triglyceride levels $(\geq 205 \mathrm{mg} / \mathrm{dL})[68,69]$.

Adequate treatment of hypertension in diabetic patients is of paramount importance. A target blood pressure of less than 140/90 $\mathrm{mm} \mathrm{Hg}$, with a benefit from angiotensin converting enzyme inhibitors or angiotensin receptor blocker in patients with concomitant cardiovascular, cerebrovascular or peripher- al vascular disease has been repeatedly demonstrated [70-73]. Despite the previously recommended stricter blood pressure target of less than 130/80 $\mathrm{mm} \mathrm{Hg}$ in the JNC 7 guideline [74], targeting a systolic blood pressure of less than $120 \mathrm{~mm} \mathrm{Hg}$, as compared with less than $140 \mathrm{~mm} \mathrm{Hg}$ was not shown to improve cardiovascular outcomes [75]. The most recent JNC 8 guidelines take this into consideration and recommend targeting a blood pressure of less than $140 / 90 \mathrm{~mm} \mathrm{Hg}$ in diabetic patients [76].

Control of hyperglycemia in diabetic patients using metformin with a target $\mathrm{A} 1 \mathrm{C}$ of less than $7.0 \%$ has been shown to be beneficial in improving cardiovascular outcomes [77]. Stricter A1C targets of 6.0-6.5\%, however, were not shown to be superior to a target of less than $7.0 \%$, and may even be harmful $[78,79]$.

The benefits of antiplatelet therapy in the setting of established cardiovascular disease, and acute coronary syndromes, have been demonstrated, including the diabetic patient subsets, in multiple clinical studies utilizing aspirin [80,81], or combination therapy with or without intervention $[82,83]$. The role of antiplatelet therapy in the setting of peripheral vascular dis- 
ease and diabetes has been less clear $[84,85]$.

\section{Conclusion}

Vascular disease in diabetic patients is an ongoing, but slowly unraveling, conundrum. The complex interplay of multiple pathways (Fig. 1), some of which were detailed in this review, appears to contribute in part to the increasing morbidity and early death of diabetic patients, especially when the diabetes is suboptimally controlled. However, despite the exponential discoveries of various metabolic pathways, little has so far translated into effective patient care.

Our case represents one of the shortcomings of care for the diabetic patient, whereby a seemingly well controlled lipid profile was associated with extensive cardiovascular and neurovascular abnormalities, due to the poorly understood, but highly aggressive, atherogenic dyslipidemia. Robust disease management programs should be advocated to better assess and treat individual patients at earlier stages, so that preventive measures can be properly implemented, accounting for nontraditional, in addition to traditional, risk factors. Additional research is needed to further elucidate the complex mechanisms involved in the interplay between these risk factors, so that newer therapeutic modalities can be rapidly advanced.

\section{References}

1. Wild S, Roglic G, Green A, Sicree R, King H. Global prevalence of diabetes: estimates for the year 2000 and projections for 2030. Diabetes Care. 2004;27(5):10471053.

2. Amos AF, McCarty DJ, Zimmet P. The rising global burden of diabetes and its complications: estimates and projections to the year 2010. Diabet Med. 1997;14(Suppl 5):S1-85.

3. Fox CS, Coady S, Sorlie PD, D'Agostino RB, Sr., Pencina MJ, Vasan RS, Meigs JB, et al. Increasing cardiovascular disease burden due to diabetes mellitus: the Framingham Heart Study. Circulation. 2007;115(12):1544-1550.

4. Fox CS, Coady S, Sorlie PD, Levy D, Meigs JB, D'Agostino RB, Sr., Wilson PW, et al. Trends in cardiovascular complications of diabetes. JAMA. 2004;292(20):2495-2499.

5. Meigs JB. Epidemiology of type 2 diabetes and cardiovascular disease: translation from population to prevention: the Kelly West award lecture 2009. Diabetes Care. 2010;33(8):1865-1871.

6. Rutter MK, Meigs JB, Sullivan LM, D'Agostino RB, Sr., Wilson PW. Insulin resistance, the metabolic syndrome, and incident cardiovascular events in the Framingham Offspring Study. Diabetes. 2005;54(11):3252-3257.

7. Paneni F, Beckman JA, Creager MA, Cosentino F. Diabetes and vascular disease: pathophysiology, clinical consequences, and medical therapy: part I. Eur Heart J. 2013;34(31):2436-2443.

8. Grundy SM, Howard B, Smith S, Jr., Eckel R, Redberg R, Bonow RO. Prevention Conference VI: Diabetes and Cardiovascular Disease: executive summary: conference proceeding for healthcare professionals from a special writing group of the American Heart Association. Circulation. 2002;105(18):2231-2239.

9. Maahs DM, Daniels SR, de Ferranti SD, Dichek HL, Flynn J, Goldstein BI, Kelly AS, et al. Cardiovascular disease risk factors in youth with diabetes mellitus: a scientific statement from the American Heart Association. Circulation. 2014;130(17):1532-1558.

10. Kampoli AM, Tousoulis D, Marinou K, Siasos G, Stefanadis C. Vascular Effects of Diabetes Mellitus. Vascular Disease Prevention. 2009;6:85-90.

11. Vinik AI, Nevoret ML, Casellini C, Parson H. Diabetic neuropathy. Endocrinol Metab Clin North Am. 2013;42(4):747-787.

12. Kaur S, Pandhi P, Dutta P. Painful diabetic neuropathy: an update. Ann Neurosci. 2011;18(4):168-175.

13. Hernandez-Ojeda J, Roman-Pintos LM, Rodriguez-Carrizalez AD, Troyo-Sanroman R, Cardona-Munoz EG, Alatorre-Carranza Mdel P, Miranda-Diaz AG. Effect of rosuvastatin on diabetic polyneuropathy: a randomized, double-blind, placebo-controlled Phase IIa study. Diabetes Metab Syndr Obes. 2014;7:401-407.

14. Spallone V, Ziegler D, Freeman R, Bernardi L, Frontoni S, Pop-Busui R, Stevens M, et al. Cardiovascular autonomic neuropathy in diabetes: clinical impact, assessment, diagnosis, and management. Diabetes Metab Res Rev. 2011;27(7):639-653.

15. Tarvainen MP, Laitinen TP, Lipponen JA, Cornforth DJ, Jelinek HF. Cardiac autonomic dysfunction in type 2 diabetes - effect of hyperglycemia and disease duration. Front Endocrinol (Lausanne). 2014;5:130.

16. Dimitropoulos G, Tahrani AA, Stevens MJ. Cardiac autonomic neuropathy in patients with diabetes mellitus. World J Diabetes. 2014;5(1):17-39.

17. Low PA, Benrud-Larson LM, Sletten DM, Opfer-Gehrking TL, Weigand SD, O'Brien PC, Suarez GA, et al. Autonomic symptoms and diabetic neuropathy: a populationbased study. Diabetes Care. 2004;27(12):2942-2947.

18. van Ravenswaaij-Arts CM, Kollee LA, Hopman JC, Stoelinga GB, van Geijn HP. Heart rate variability. Ann Intern Med. 1993;118(6):436-447.

19. Vinik AI, Ziegler D. Diabetic cardiovascular autonomic neuropathy. Circulation. 2007;115(3):387-397.

20. Karayannis G, Giamouzis G, Cokkinos DV, Skoularigis J, Triposkiadis F. Diabetic cardiovascular autonomic neuropathy: clinical implications. Expert Rev Cardiovasc Ther. 2012;10(6):747-765.

21. Collins-Nakai RL, Noseworthy D, Lopaschuk GD. Epinephrine increases ATP production in hearts by preferentially increasing glucose metabolism. Am J Physiol. 1994;267(5 Pt 2):H1862-1871.

22. Nesto RW, Phillips RT, Kett KG, Hill T, Perper E, Young $\mathrm{E}$, Leland OS, Jr. Angina and exertional myocardial ischemia in diabetic and nondiabetic patients: assessment by exercise thallium scintigraphy. Ann Intern Med. 1988;108(2):170-175.

23. Chiariello $\mathrm{M}$, Indolfi $\mathrm{C}$. Silent myocardial ischemia in patients with diabetes mellitus. Circulation. 1996;93(12):2089-2091. 
24. Zellweger MJ. Prognostic significance of silent coronary artery disease in type 2 diabetes. Herz. 2006;31(3):240245.

25. Valensi P, Lorgis L, Cottin Y. Prevalence, incidence, predictive factors and prognosis of silent myocardial infarction: a review of the literature. Arch Cardiovasc Dis. 2011;104(3):178-188.

26. Shirani J, Dilsizian V. Screening asymptomatic patients with type 2 diabetes mellitus for coronary artery disease: does it improve patient outcome? Curr Cardiol Rep. 2010;12(2):140-146.

27. Gandaglia G, Salonia A, Passoni N, Montorsi P, Briganti A, Montorsi F. Erectile dysfunction as a cardiovascular risk factor in patients with diabetes. Endocrine. 2013;43(2):285-292.

28. Hoeks S, Flu WJ, van Kuijk JP, Bax J, Poldermans D. Cardiovascular risk assessment of the diabetic patient undergoing major noncardiac surgery. Best Pract Res Clin Endocrinol Metab. 2009;23(3):361-373.

29. Kent BD, Grote L, Ryan S, Pepin JL, Bonsignore MR, Tkacova R, Saaresranta T, et al. Diabetes mellitus prevalence and control in sleep-disordered breathing: the European Sleep Apnea Cohort (ESADA) study. Chest. 2014;146(4):982-990.

30. Nannapaneni S, Ramar K, Surani S. Effect of obstructive sleep apnea on type 2 diabetes mellitus: A comprehensive literature review. World J Diabetes. 2013;4(6):238-244.

31. Suarez GA, Clark VM, Norell JE, Kottke TE, Callahan MJ, O'Brien PC, Low PA, et al. Sudden cardiac death in diabetes mellitus: risk factors in the Rochester diabetic neuropathy study. J Neurol Neurosurg Psychiatry. 2005;76(2):240-245.

32. Bergner DW, Goldberger JJ. Diabetes mellitus and sudden cardiac death: what are the data? Cardiol J. 2010;17(2):117-129.

33. McCord JM, Omar BA. Sources of free radicals. Toxicol Ind Health. 1993;9(1-2):23-37.

34. Guzik TJ, Mussa S, Gastaldi D, Sadowski J, Ratnatunga C, Pillai R, Channon KM. Mechanisms of increased vascular superoxide production in human diabetes mellitus: role of $\mathrm{NAD}(\mathrm{P}) \mathrm{H}$ oxidase and endothelial nitric oxide synthase. Circulation. 2002;105(14):1656-1662.

35. Koppenol WH, Moreno JJ, Pryor WA, Ischiropoulos H, Beckman JS. Peroxynitrite, a cloaked oxidant formed by nitric oxide and superoxide. Chem Res Toxicol. 1992;5(6):834-842.

36. Hink U, Li H, Mollnau H, Oelze M, Matheis E, Hartmann M, Skatchkov M, et al. Mechanisms underlying endothelial dysfunction in diabetes mellitus. Circ Res. 2001;88(2):E14-22.

37. McCord JM, Omar BA. Mechanisms of ischemia/reperfusion injury. u: Davies K.J.A. (ur.) Oxidative damage and repair: Chemical, biological and medical aspects, OxfordNew York, itd: Pergamon Press, str. 1991;396-401.

38. Beckman JA, Goldfine AB, Gordon MB, Creager MA. Ascorbate restores endothelium-dependent vasodilation impaired by acute hyperglycemia in humans. Circulation. 2001;103(12):1618-1623.

39. Omar BA, Flores SC, McCord JM. Superoxide dis- mutase: pharmacological developments and applications. Adv Pharmacol. 1992;23:109-161.

40. Cohen RA. Role of nitric oxide in diabetic complications. Am J Ther. 2005;12(6):499-502.

41. Tessari P. Nitric oxide in the normal kidney and in patients with diabetic nephropathy. J Nephrol. 2015;28(3):257268.

42. Duran-Salgado MB, Rubio-Guerra AF. Diabetic nephropathy and inflammation. World J Diabetes. 2014;5(3):393398.

43. Sandireddy R, Yerra VG, Areti A, Komirishetty P, Kumar A. Neuroinflammation and oxidative stress in diabetic neuropathy: futuristic strategies based on these targets. Int J Endocrinol. 2014;2014:674987.

44. Elahy M, Baindur-Hudson S, Cruzat VF, Newsholme $\mathrm{P}$, Dass CR. Mechanisms of PEDF-mediated protection against reactive oxygen species damage in diabetic retinopathy and neuropathy. J Endocrinol. 2014;222(3):R129139.

45. Xu J, Zhao YH, Chen YP, Yuan XL, Wang J, Zhu H, Lu CM. Maternal circulating concentrations of tumor necrosis factor-alpha, leptin, and adiponectin in gestational diabetes mellitus: a systematic review and meta-analysis. ScientificWorldJournal. 2014;2014:926932.

46. Mushtaq G, Khan JA, Kamal MA. Biological mechanisms linking Alzheimer's disease and type-2 diabetes mellitus. CNS Neurol Disord Drug Targets. 2014;13(7):1192-1201.

47. Varga ZV, Giricz Z, Liaudet L, Hasko G, Ferdinandy $\mathrm{P}$, Pacher P. Interplay of oxidative, nitrosative/nitrative stress, inflammation, cell death and autophagy in diabetic cardiomyopathy. Biochim Biophys Acta. 2015; 1852(2):232-242.

48. Ziegler D, Buchholz S, Sohr C, Nourooz-Zadeh J, Roden M. Oxidative stress predicts progression of peripheral and cardiac autonomic nerve dysfunction over 6 years in diabetic patients. Acta Diabetol. 2015;52(1):65-72.

49. Thiyagarajan R, Subramanian SK, Sampath N, Madanmohan T, Pal P, Bobby Z, Paneerselvam S, et al. Association between cardiac autonomic function, oxidative stress and inflammatory response in impaired fasting glucose subjects: cross-sectional study. PLoS One. 2012;7(7):e41889.

50. Manzella D, Barbieri M, Ragno E, Paolisso G. Chronic administration of pharmacologic doses of vitamin $\mathrm{E}$ improves the cardiac autonomic nervous system in patients with type 2 diabetes. Am J Clin Nutr. 2001;73(6):10521057.

51. Beckman JA, Paneni F, Cosentino F, Creager MA. Diabetes and vascular disease: pathophysiology, clinical consequences, and medical therapy: part II. Eur Heart J. 2013;34(31):2444-2452.

52. Matheus AS, Tannus LR, Cobas RA, Palma CC, Negrato CA, Gomes MB. Impact of diabetes on cardiovascular disease: an update. Int J Hypertens. 2013;2013:653789.

53. Pasterkamp G. Methods of accelerated atherosclerosis in diabetic patients. Heart. 2013;99(10):743-749.

54. Puri R, Kataoka Y, Uno K, Nicholls SJ. The distinctive nature of atherosclerotic vascular disease in diabetes: pathophysiological and morphological insights. Curr Diab Rep. 2012;12(3):280-285. 
55. Li H, Horke S, Forstermann U. Vascular oxidative stress, nitric oxide and atherosclerosis. Atherosclerosis. 2014;237(1):208-219.

56. Del Turco S, Basta G. An update on advanced glycation endproducts and atherosclerosis. Biofactors. 2012;38(4):266-274.

57. Sun JT, Shen Y, Lu AK, Lu L, Shen WF. Glycation of high-density lipoprotein in type 2 diabetes mellitus. Chin Med J (Engl). 2013;126(21):4162-4165.

58. Yoo HJ, Choi KM. Adipokines as a novel link between obesity and atherosclerosis. World J Diabetes. 2014;5(3):357-363.

59. Fantuzzi G. Adiponectin and inflammation: consensus and controversy. J Allergy Clin Immunol. 2008;121(2):326330.

60. Kishida K, Funahashi T, Shimomura I. Molecular mechanisms of diabetes and atherosclerosis: role of adiponectin. Endocr Metab Immune Disord Drug Targets. 2012;12(2):118-131.

61. Fowler MJ. Microvascular and Macrovascular Complications of Diabetes. Clinical Diabetes. 2008;26(2).

62. Grundy SM. Small LDL, atherogenic dyslipidemia, and the metabolic syndrome. Circulation. 1997;95(1):1-4.

63. Martin-Timon I, Sevillano-Collantes C, Segura-Galindo A, Del Canizo-Gomez FJ. Type 2 diabetes and cardiovascular disease: Have all risk factors the same strength? World J Diabetes. 2014;5(4):444-470.

64. Collins R, Armitage J, Parish S, Sleigh P, Peto R. MRC/ BHF Heart Protection Study of cholesterol-lowering with simvastatin in 5963 people with diabetes: a randomised placebo-controlled trial. Lancet. 2003;361(9374):20052016.

65. Colhoun HM, Betteridge DJ, Durrington PN, Hitman GA, Neil HA, Livingstone SJ, Thomason MJ, et al. Primary prevention of cardiovascular disease with atorvastatin in type 2 diabetes in the Collaborative Atorvastatin Diabetes Study (CARDS): multicentre randomised placebo-controlled trial. Lancet. 2004;364(9435):685-696.

66. Ginsberg HN, Elam MB, Lovato LC, Crouse JR, 3rd, Leiter LA, Linz P, Friedewald WT, et al. Effects of combination lipid therapy in type 2 diabetes mellitus. N Engl J Med. 2010;362(17):1563-1574.

67. Boden WE, Probstfield JL, Anderson T, Chaitman BR, Desvignes-Nickens P, Koprowicz K, McBride R, et al. Niacin in patients with low HDL cholesterol levels receiving intensive statin therapy. $\mathrm{N}$ Engl $\mathrm{J}$ Med. 2011;365(24):2255-2267.

68. Sacks FM, Carey VJ, Fruchart JC. Combination lipid therapy in type 2 diabetes. N Engl J Med. 2010;363(7):692694; author reply 694-695.

69. Keech A, Simes RJ, Barter P, Best J, Scott R, Taskinen MR, Forder P, et al. Effects of long-term fenofibrate therapy on cardiovascular events in 9795 people with type 2 diabetes mellitus (the FIELD study): randomised controlled trial. Lancet. 2005;366(9500):1849-1861.

70. Major outcomes in high-risk hypertensive patients randomized to angiotensin-converting enzyme inhibitor or calcium channel blocker vs diuretic: The Antihypertensive and Lipid-Lowering Treatment to Prevent Heart At- tack Trial (ALLHAT). JAMA. 2002;288(23):2981-2997.

71. Yusuf S, Sleight P, Pogue J, Bosch J, Davies R, Dagenais G. Effects of an angiotensin-converting-enzyme inhibitor, ramipril, on cardiovascular events in high-risk patients. The Heart Outcomes Prevention Evaluation Study Investigators. N Engl J Med. 2000;342(3):145-153.

72. Pfeffer MA, McMurray JJ, Velazquez EJ, Rouleau JL, Kober L, Maggioni AP, Solomon SD, et al. Valsartan, captopril, or both in myocardial infarction complicated by heart failure, left ventricular dysfunction, or both. $\mathrm{N}$ Engl J Med. 2003;349(20):1893-1906.

73. Yusuf S, Teo KK, Pogue J, Dyal L, Copland I, Schumacher H, Dagenais G, et al. Telmisartan, ramipril, or both in patients at high risk for vascular events. N Engl J Med. 2008;358(15):1547-1559.

74. Chobanian AV, Bakris GL, Black HR, Cushman WC, Green LA, Izzo JL, Jr., Jones DW, et al. The Seventh Report of the Joint National Committee on Prevention, Detection, Evaluation, and Treatment of High Blood Pressure: the JNC 7 report. JAMA. 2003;289(19):2560-2572.

75. Cushman WC, Evans GW, Byington RP, Goff DC, Jr., Grimm RH, Jr., Cutler JA, Simons-Morton DG, et al. Effects of intensive blood-pressure control in type 2 diabetes mellitus. N Engl J Med. 2010;362(17):1575-1585.

76. James PA, Oparil S, Carter BL, Cushman WC, Dennison-Himmelfarb C, Handler J, Lackland DT, et al. 2014 evidence-based guideline for the management of high blood pressure in adults: report from the panel members appointed to the Eighth Joint National Committee (JNC 8). JAMA. 2014;311(5):507-520.

77. Holman RR, Paul SK, Bethel MA, Matthews DR, Neil HA. 10-year follow-up of intensive glucose control in type 2 diabetes. N Engl J Med. 2008;359(15):1577-1589.

78. Gerstein HC, Miller ME, Byington RP, Goff DC, Jr., Bigger JT, Buse JB, Cushman WC, et al. Effects of intensive glucose lowering in type 2 diabetes. N Engl J Med. 2008;358(24):2545-2559.

79. Patel A, MacMahon S, Chalmers J, Neal B, Woodward M, Billot L, Harrap S, et al. Effects of a fixed combination of perindopril and indapamide on macrovascular and microvascular outcomes in patients with type 2 diabetes mellitus (the ADVANCE trial): a randomised controlled trial. Lancet. 2007;370(9590):829-840.

80. Randomised trial of intravenous streptokinase, oral aspirin, both, or neither among 17,187 cases of suspected acute myocardial infarction: ISIS-2. ISIS-2 (Second International Study of Infarct Survival) Collaborative Group. Lancet. 1988;2(8607):349-360.

81. Collaborative meta-analysis of randomised trials of antiplatelet therapy for prevention of death, myocardial infarction, and stroke in high risk patients. BMJ. 2002;324(7329):71-86.

82. Yusuf S, Zhao F, Mehta SR, Chrolavicius S, Tognoni G, Fox KK. Effects of clopidogrel in addition to aspirin in patients with acute coronary syndromes without ST-segment elevation. N Engl J Med. 2001;345(7):494-502.

83. Wiviott SD, Braunwald E, Angiolillo DJ, Meisel S, Dalby AJ, Verheugt FW, Goodman SG, et al. Greater clinical benefit of more intensive oral antiplatelet ther- 
apy with prasugrel in patients with diabetes mellitus in the trial to assess improvement in therapeutic outcomes by optimizing platelet inhibition with prasugrelThrombolysis in Myocardial Infarction 38. Circulation. 2008;118(16):1626-1636.

84. Ogawa H, Nakayama M, Morimoto T, Uemura S, Kanauchi M, Doi N, Jinnouchi H, et al. Low-dose aspirin for primary prevention of atherosclerotic events in pa- tients with type 2 diabetes: a randomized controlled trial. JAMA. 2008;300(18):2134-2141.

85. Belch J, MacCuish A, Campbell I, Cobbe S, Taylor R, Prescott R, Lee R, et al. The prevention of progression of arterial disease and diabetes (POPADAD) trial: factorial randomised placebo controlled trial of aspirin and antioxidants in patients with diabetes and asymptomatic peripheral arterial disease. BMJ. 2008;337:a1840. 